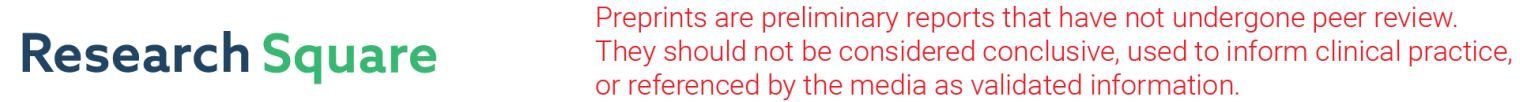 \\ Social Perspective of Female Genital Mutilation/Cutting in Khartoum State - Sudan 2020
}

\author{
Mustafa Khidir Mustafa Elnimeiri
}

ALneelain University

Shahenaz seifalseen Mustafa Satti ( $\nabla$ shahenazsatti@gmail.com )

Alneelain University https://orcid.org/0000-0002-9265-4794

\section{Taqwa Mohieldeen Hamid Abdelrahim}

central bureau statistics

Mohanad Kamaleldin Mahmoud Ibrahim

"DeVry University"

Reem Mahmoud Mohamed Abdelbasit

Alneelain University

Dimetry Adel Dimetry Mingaryous

ALneelain university

\section{Research}

Keywords: Female genital cutting, Social Factors, Violation, Sudan

Posted Date: August 2nd, 2020

DOI: https://doi.org/10.21203/rs.3.rs-49042/v1

License: (c) (i) This work is licensed under a Creative Commons Attribution 4.0 International License.

Read Full License 


\title{
Social Perspective of Female Genital Mutilation/Cutting in Khartoum State - Sudan
} 2020

First auther

Dr. Mustafa Khidir Mustafa Elnimeiri

\author{
MB. Bch. MD \\ Professor of Preventive Medicine \& Epidemiology \\ Al-Neelain University \\ Khartoum, Sudan \\ Email: nimeirimust@gmail.com \\ Co auther 1 correspoding auther \\ Dr. Shahenaz Seifaldeen Mustafa Satti \\ MBBS, Msc Clinical Physiology \\ Lecturer of Physiology \\ Faculty of Medicine, Al-Neelain University \\ Khartoum, Sudan \\ E-mail: shahenazsatti@gmail.com \\ Co auther 2
}

Ms. Taqwa Mohieldeen Hamid Abdelrahim

BSc, MSc Statistics

Statistician at Central Bureau of Statistics

Khartoum, Sudan.

E-mail: taqwa.mohi2015@gmail.com

Coauther 3 


\title{
Dr. Mohanad Kamaleldin Mahmoud Ibrahim.
}

MBBS, MPH, PhD

Assistant Professor of Community Medicine.

Ibn Sina University, Faculty of Medicine - Department of Community Medicine

Khartoum, Sudan

E-mail: drmuhanadkamal@hotmail.com

Co auther 4

\section{Dr. Reem Mahmoud Mohamed Abdelbasit}

MBBS, MPH Candidate

Teaching Assistant - Community Medicine Department

Al-Neelain University, Faculty of Medicine

Khartoum, Sudan

E-mail: Rymmahmoud@gmail.com

Co auther 5

\section{Dr. Dimetry Adel Dimetry Mingaryous}

\author{
MBBS, MPH candidate \\ Lecturer - Department of Community Medicine \\ Sudan International University, Faculty of Medicine \\ Khartoum, Sudan
}

Email: Dimtry1@gmail.com 


\begin{abstract}
Background: Female genital cutting (FGC) comprises all procedures that involve partial or total removal of the external female genitalia, or other injury to the female organs for non-medical reasons and it is considered as violation of human rights of girls and women. The overall objective of this study was to explore the social factors contributing in the persistence of this practice despite of the efforts for eradication in Khartoum State-
\end{abstract}

Methods: This was a community based cross-sectional study conducted in Khartoum State- Sudan including the three localities. The study included 920 females within the reproductive age, sampled proportionate to size using multistage cluster sampling The data were collected using standardized administered questionnaire, Data were analyzed using statistical package for social science's version 21. Analysis was composed of descriptive data and Multinominal Regression Test to study the associations between variables of interest.

\title{
Results:
}

$62 \%$ of the participants considered female genital cutting as a violation of girls' and women's rights, $20 \%$ of them mentioned rejection by husbands as the main risk if daughters were not subjected to female genital cutting ,71\% of the participants considered female genital cutting as a harmful traditional practice while $26 \%$ did not consider it as such . ] Multinomial logistic regression estimates of daughters have been subjected to any form of female genital cutting and reasons of conduct of female genital cutting and the risk encountered when girls are not subjected to female genital cutting showed " the risk encountered when girls are not subjected to female genital cutting" ranked the first place in influence as the regression coefficient of this variable is 68.779, 
while the main reason for the conduct of female genital cutting ranked the second place in influence as the regression coefficient of this variable is .089 .

Conclusions: FGC is a cultural practice recognized as a violation of human rights. These findings support the social coordination norm model, and results indicate the widely prevailing misconceptions about FGC/M among the study participants especially among those participants supporting the continuation of FGC/M.

\section{Key words}

Female genital cutting, Social Factors, Violation, Sudan 
Abbreviation

FGM:

FGC/M

MICS

SDGs

$\mathrm{RH}$

NPC

UN

SFPA

SNCTP

NGOs

SPSS

IEC

df

$\mathrm{FMOH}$

$\mathrm{SD}$

WHO
Female genital mutilation

Female genital cutting /mutilation

Multiple Indicator Cluster Survey

Sustainable Development Goals

Reproductive health

National Population Council

United Nations

Sudan Family Planning Association

Sudan National Committee on Traditional Practice

Non-governmental organizations

Statistical Package for Social Sciences

Information, education \& communication

degree of freedom

Federal Ministry of Health

Standard deviation

World Health Organization 


\section{Background}

Female genital mutilation (FGM) comprises all procedures that involve partial or total removal of the external female genitalia, or other injury to the female genital organs for non-medical reasons(Mseddi et al., 2020). FGM is mostly carried out on young girls between infancy and age 15 and it is considered as violation of human rights of girls and women("Female Genital Mutilation/Cutting: A Statistical Overview and Exploration of the Dynamics of Change," 2013) .

More than 200 million girls and women alive today have been cut in 30 countries in Africa, the Middle East and Asia where FGM is concentrated (Wright, 1996)

Inspire intensified efforts to reduce FGC/M in Sudan but the practice continues, the Multiple Indicator Cluster Survey (MICS) 2104 revealed that 86.6\% of women aged 1549 years were subjected to any form of FGC/M(Cuba Multiple Indicator Cluster Survey 2014 _ GHDx, n.d.) . However, reduction in the prevalence of FGC/M is observed in most of the states but at different levels. For example, if we compared the FGC/M prevalence rate reported by the Safe Motherhood Survey, 90.1\%(Evaluation Branch DOS, 2012) with the recent prevalencevrate by the MICS. The reduction is slow and lagging behind what the situation demands.

The harmful traditional practices were integrated into Sustainable Development Goals (SDGs), specifically Target 5.3 which called for eradication of FGM by the year 2030 (WHO, 2015).

The eradication of FGC/M has been included within the national RH and other sectoral policies and strategies and the concerned bodies emanated interventional programs across the country but still the reduction in the prevalence is slow and lagging behind. FGC is carried out for a range of social and cultural, traditional reasons, in some cultures, parents submit their daughters to FGC not as a means of punishment or abuse, but as deeply rooted beliefs, they think FGC will give them social acceptance. FGC is 
performed in order to prepare girls for adulthood and marriage; to ensure their virginity until marriage; to ensure their fidelity in marriage; in certain communities, it is thought to increase fertility and to enhance the sexual pleasure of men(Gruenbaum, 2005). Men play a role by preferring to marry a woman who has undergone FGC, or by insisting that it be performed on their daughters.

The aim of this study is defining the identity of women in cultures where it is practiced, to explore the social factors that will help in generation of valuable information for the policy and decision-makers to upgrade the current policies and strategies to accomplish FGC/M eradication by the year 2030 .

\section{Methods:}

This a community based cross-sectional study was conducted in Khartoum State; the capital of Sudan with an area of about $22.122 \mathrm{~km}^{2}$. The study included three localities; Khartoum North Locality, Sharq an-Nîl Locality and Umbadda Locality.

The study concerned with women in the reproductive age (15-49) and the total census of women at this age in Khartoum State, projection 2018 estimated as 2,014,382 (25.2\%). The sample size was estimated using the population formula $n=N / 1+\left(N^{*} d^{2}\right)$ and calculated as 920 participants considering the design effect of 2 and response rate at $15 \%$.

The sample size was collected proportionate to size using multistage cluster sampling ,the data were collected using pre-coded, pretested administered questionnaire. Data were managed and Descriptive analysis was completed for background information and bi-variate analysis for cross-tabulation using Multinominal RegressionTest, we was performed to study the associations using The Social Program for Statistical Analysis (SPSS) version 21.

\section{Results}


Table (1): Personal characteristic of the study participants

\begin{tabular}{|c|c|c|}
\hline Characteristics & Frequency & Percentage \\
\hline \multicolumn{3}{|l|}{ Age in years } \\
\hline$<20$ & 15 & 1.6 \\
\hline 20- 24 years & 60 & 6.5 \\
\hline 25-29 years & 125 & 13.6 \\
\hline 30-34 years & 164 & 17.8 \\
\hline $35-39$ years & 190 & 20.7 \\
\hline $40-44$ years & 150 & 16.3 \\
\hline$>44$ years & 216 & 23.5 \\
\hline Total & 920 & 100.0 \\
\hline \multicolumn{3}{|l|}{ Marital status } \\
\hline Married & 817 & 88.8 \\
\hline Divorced & 37 & 4.0 \\
\hline Widowed & 60 & 6.5 \\
\hline Separated & 6 & 0.7 \\
\hline Total & 920 & 100.0 \\
\hline \multicolumn{3}{|l|}{ Age of marriage at first time } \\
\hline$<20$ & 438 & 47.6 \\
\hline 20- 24 years & 259 & 28.2 \\
\hline 25-29 years & 161 & 17.5 \\
\hline $30-34$ years & 50 & 5.4 \\
\hline $35-39$ years & 9 & 1.0 \\
\hline $40-44$ years & 2 & 0.2 \\
\hline$>44$ years & 1 & 0.1 \\
\hline Total & 920 & 100.0 \\
\hline \multicolumn{3}{|l|}{ Religion } \\
\hline Moslem & 918 & 99.8 \\
\hline Christian & 2 & 0.2 \\
\hline Total & 920 & 100.0 \\
\hline \multicolumn{3}{|l|}{ Current residence } \\
\hline Urban & 713 & 77.5 \\
\hline Rural & 20 & 2.2 \\
\hline Peri-urban & 187 & 20.3 \\
\hline Total & 920 & 100.0 \\
\hline
\end{tabular}

About $89 \%$ of the study participants were married and $48 \%$ of them got married for the first time at age less than 20 years. $99.8 \%$ of the study participants were Moslems and $77.5 \%$ were currently urban resident 


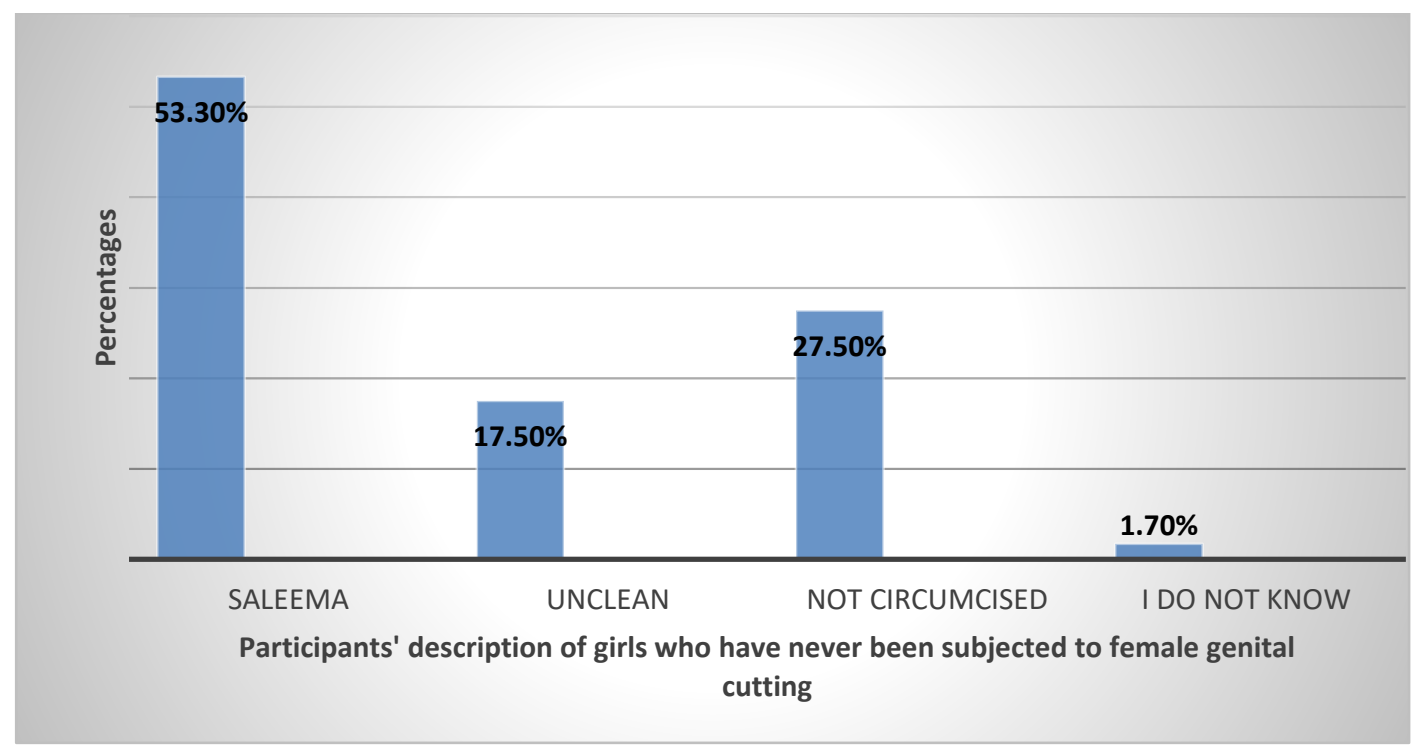

Figure (I): Participants' description of girls who have never been subjected to female genital cutting

$53 \%$ of the study participants described girls who have never been subjected female genital cutting as Saleema while $28 \%$ described them as not circumcised and $18 \%$ as unclean

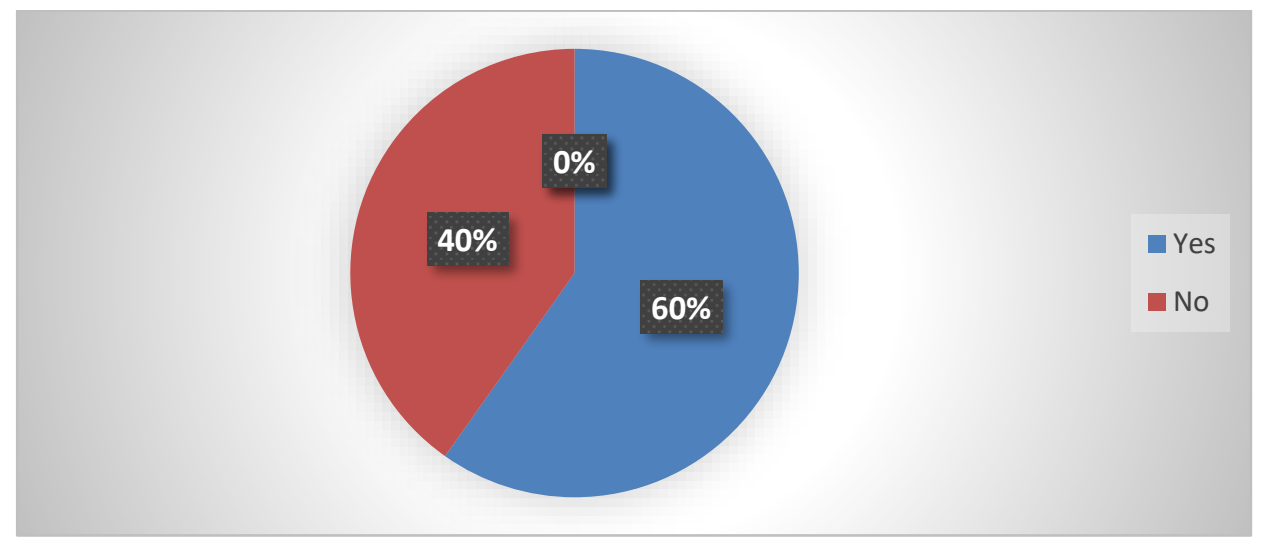

Figure (II): Participants ever discussed female genital cutting with husbands $60 \%$ of the participants ever discussed female genital cutting with their husbands while $40 \%$ never discussed it. 
Table (2): Opinions of participants' husbands about female genital cutting

\begin{tabular}{|c|c|c|}
\hline Husbands' opinion about female genital cutting & Frequency & Percentage \\
\hline Agree & 241 & 43.8 \\
\hline Disagree & 299 & 54.3 \\
\hline I do not know & 10 & 1.9 \\
\hline Total & 550 & 59.8 \\
\hline
\end{tabular}

$54 \%$ of the participants' husbands disagreed to female genital cutting while $43 \%$ of them agreed to it.

Table (3): Participants' opinion about the person influence the decision to subject their daughters to FGC/M at the family level

\begin{tabular}{|c|c|c|}
\hline $\begin{array}{c}\text { The person influences the decision to subject their daughters } \\
\text { to female genital cutting }\end{array}$ & Frequency & Percentage \\
\hline Me & 359 & 39 \\
\hline My husband & 116 & 12.6 \\
\hline Both me my husband & 10 & 1.1 \\
\hline My mother & 198 & 21.5 \\
\hline My father & 5 & 0.5 \\
\hline Husband's mother & 99 & 10.8 \\
\hline Husband's father & 13 & 1.4 \\
\hline I do not know & 11 & 1.2 \\
\hline Nobody & 90 & 9.8 \\
\hline Others & 19 & 2.1 \\
\hline Total & 920 & 100 \\
\hline
\end{tabular}

$39 \%$ of the participants stated that they themselves influence the decision to subject their daughters to female genital cutting while $32 \%$ of them stated that the grandmothers influence such decision. 


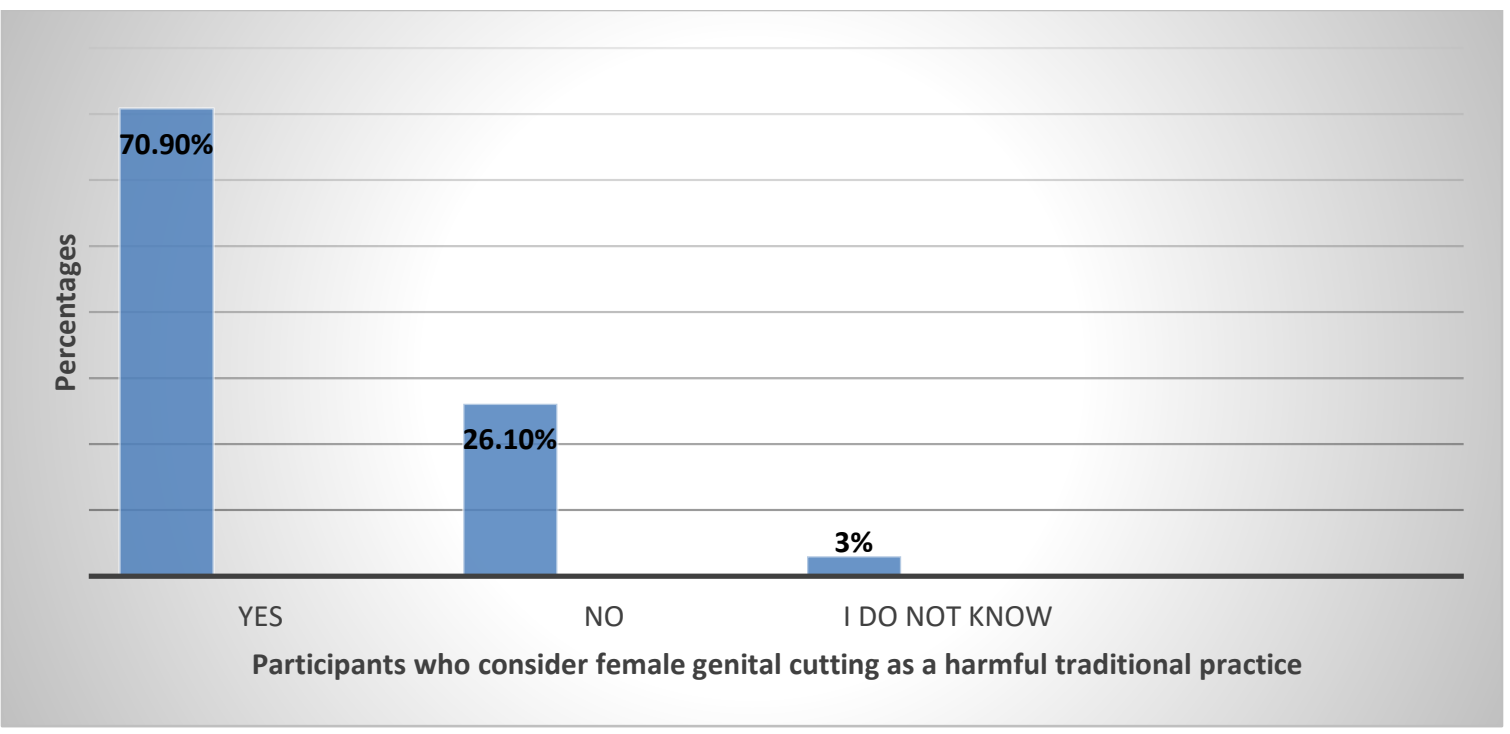

Figure (I11): Participants consider female genital cutting as a harmful traditional practice

$71 \%$ of the participants considered female genital cutting as a harmful traditional practice while $26 \%$ did not consider it as such

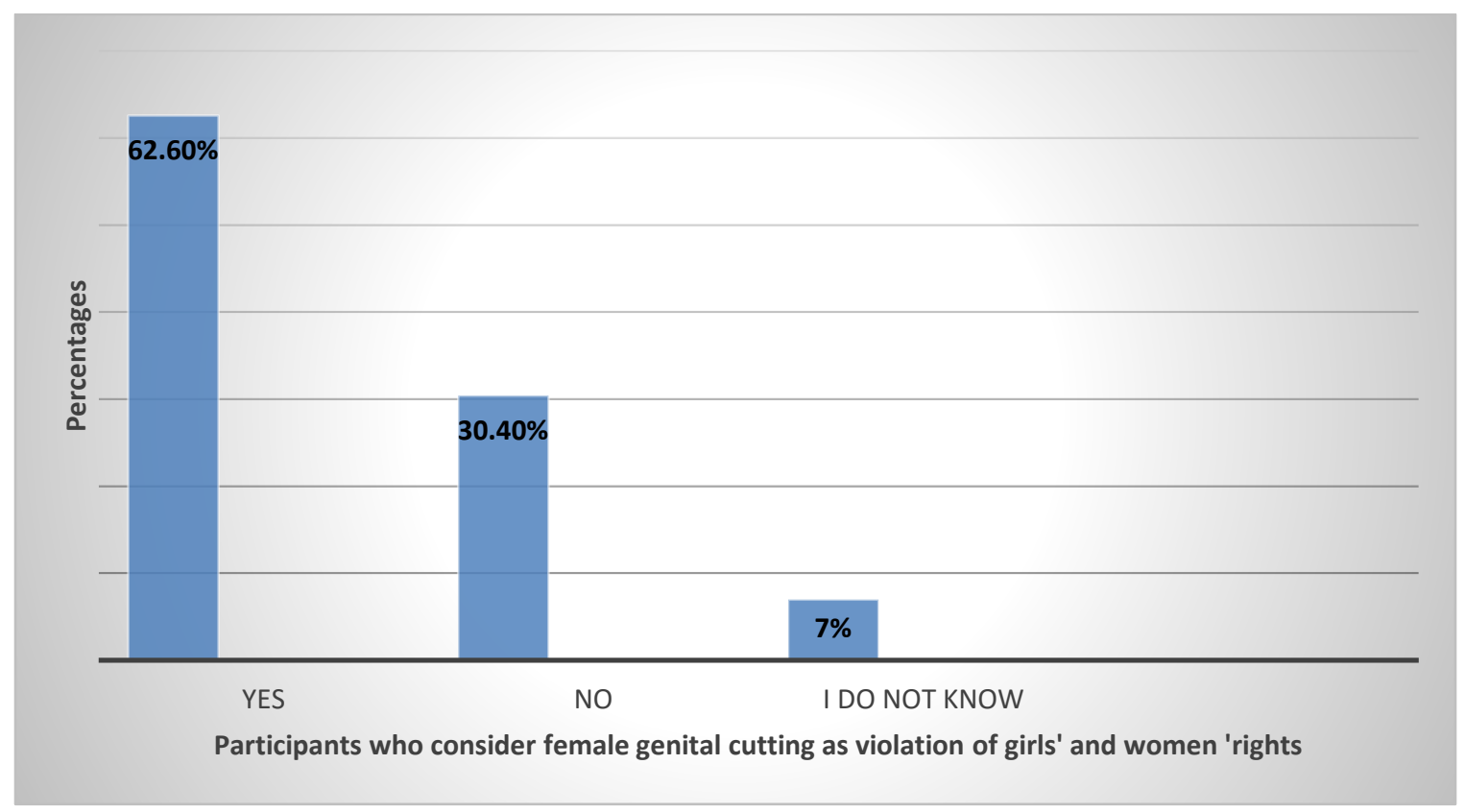

Figure (IV): Participants consider female genital cutting as a violation of girls' and women's rights

$62 \%$ of the participants considered female genital cutting as a violation of girls' and women's rights. 


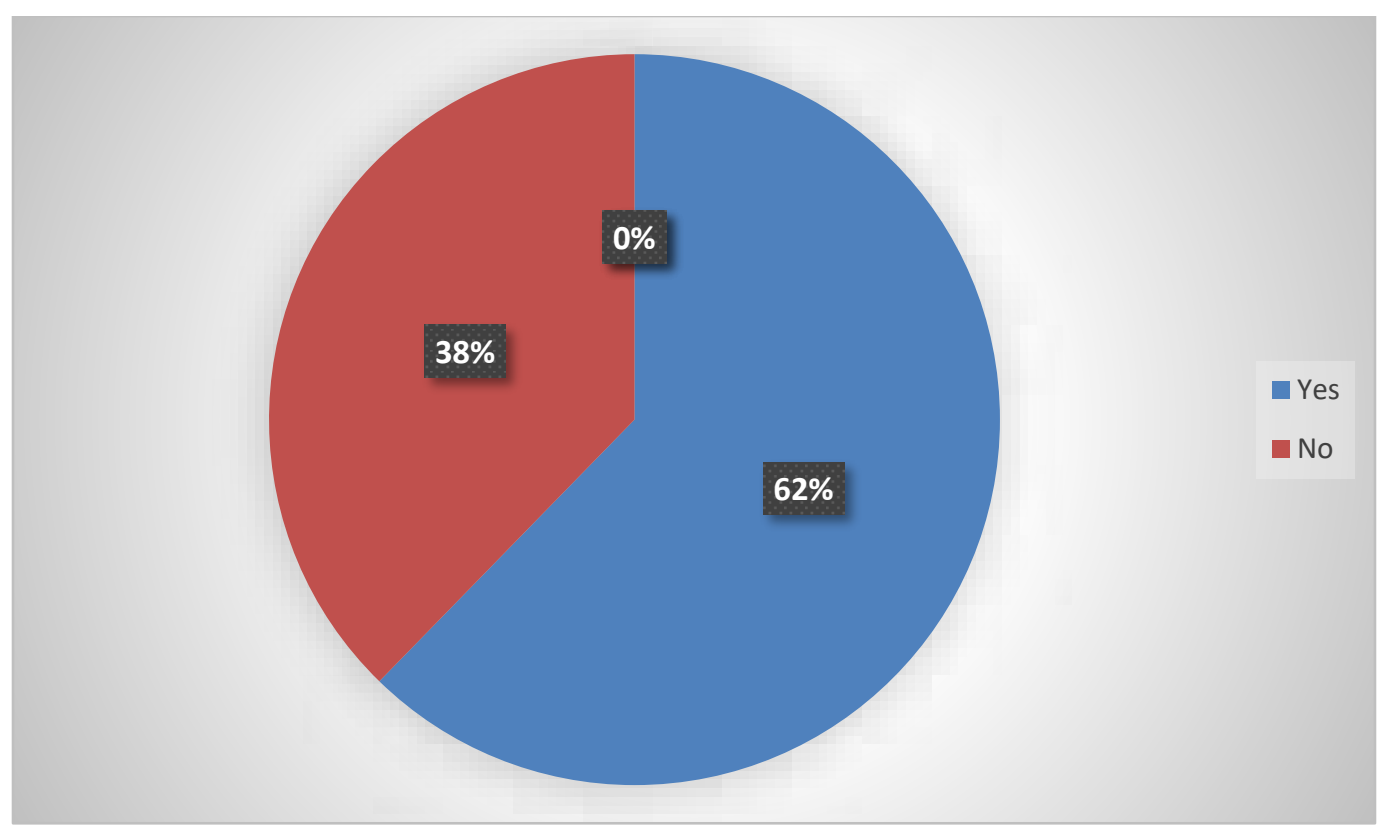

Figure (V): Participants support eradication of female genital cutting $62 \%$ supported the eradication of female genital cutting while $38 \%$ of them did not support it.

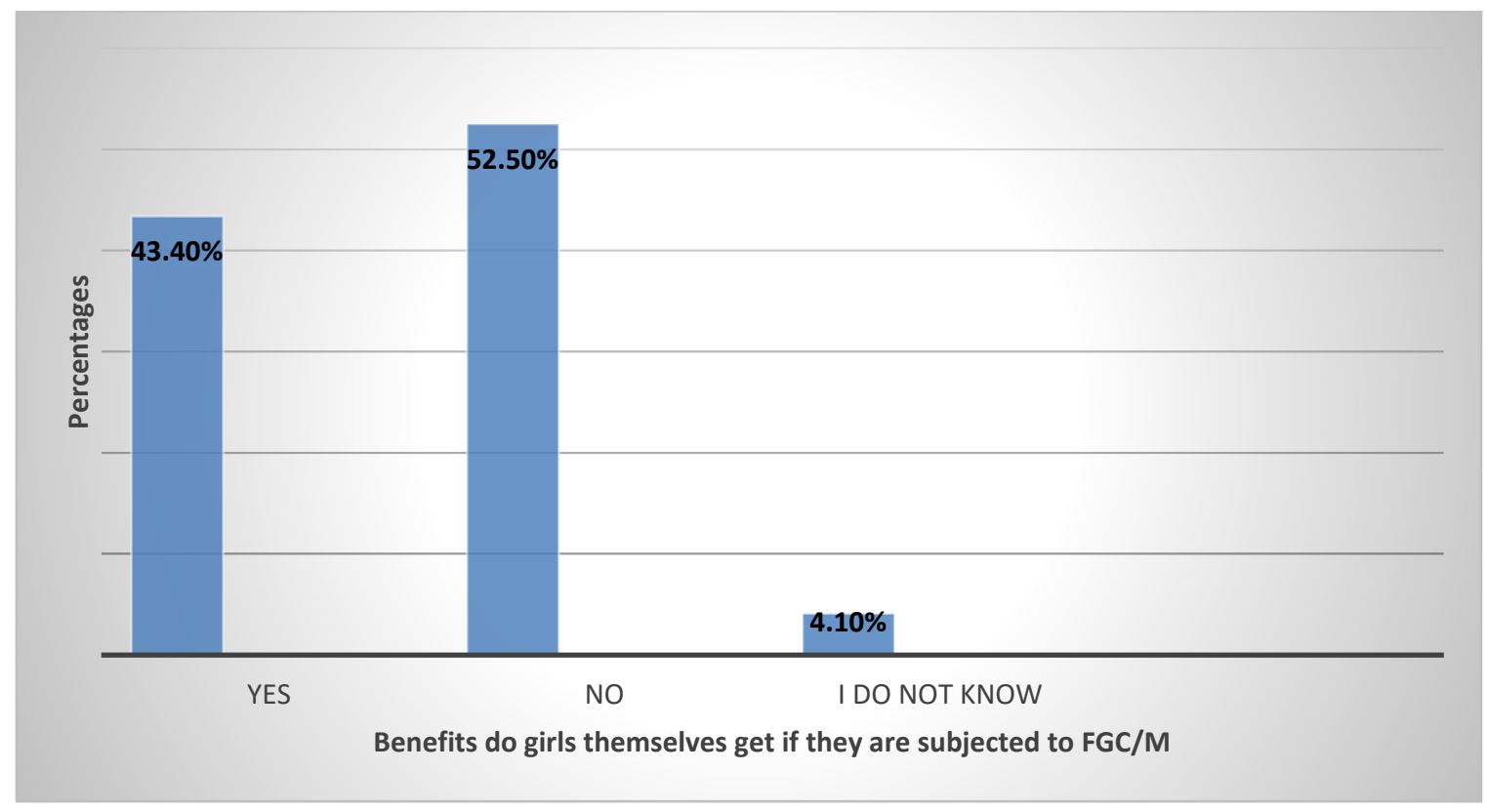

Figure (V1): Benefits do girls themselves get if they are subjected to female genital cutting

$53 \%$ of the participants denied any benefits do girls themselves get if they are subjected to female genital cutting while $43 \%$ of them stated that there were benefits. 
Table (4): The main benefit does girls themselves get if they are subjected to female genital cutting

\begin{tabular}{|c|c|c|}
\hline Benefits do girls get if subjected to female genital cutting & Frequency & Percentage \\
\hline Preservation of virginity & 135 & $\mathbf{3 3 . 8}$ \\
\hline Better marriage prospects & 46 & $\mathbf{1 1 . 5}$ \\
\hline Cleanliness/hygiene & 90 & $\mathbf{2 2 . 6}$ \\
\hline Customs \& traditions & 51 & $\mathbf{1 2 . 8}$ \\
\hline Religious approval & 42 & $\mathbf{1 0 . 5}$ \\
\hline Demanded by men & 22 & 5.5 \\
\hline Do not know & 10 & $\mathbf{2 . 5}$ \\
\hline Others & $\mathbf{3}$ & $\mathbf{0 . 8}$ \\
\hline Total & $\mathbf{3 9 9}$ & $\mathbf{1 0 0}$ \\
\hline
\end{tabular}

$34 \%$ of the participants who stated that there were benefits of female genital cutting mentioned the preservation of virginity and $23 \%$ of them mentioned cleanliness/hygiene as benefits of female genital cutting.

Table (5): The main risk encountered when daughters are not subjected to female genital cutting

\begin{tabular}{|c|c|c|}
\hline $\begin{array}{c}\text { The main risk encountered when daughters are not subjected } \\
\text { to female genital cutting }\end{array}$ & Frequency & Percentage \\
\hline Rejection by the family & 115 & 12.5 \\
\hline Rejection by their husbands & 181 & 19.7 \\
\hline Rejection by their husband's family & 32 & 3.5 \\
\hline Rejection by friends \& neighbors & 53 & 5.8 \\
\hline No risks at all & 472 & 51.3 \\
\hline I do not know & 46 & 5.0 \\
\hline Fear of community stigma & 6 & 0.7 \\
\hline Increase sexual desire & 10 & 1.1 \\
\hline Accumulation of fungi & 3 & 0.3 \\
\hline Not tallying with Sunna & 2 & 0.2 \\
\hline Total & $\mathbf{1 0 0}$ & $\mathbf{1 0 0}$ \\
\hline
\end{tabular}

$51 \%$ of the study participants stated that there was no risk at all while $20 \%$ of them mentioned rejection by husbands as the main risk if daughters were not subjected to female genital cutting. 
Table (6): Multinomial logistic regression estimates of daughters have been subjected to any form of female genital cutting and reasons of conduct of female genital cutting and the risk encountered when girls are not subjected to female genital cutting

\begin{tabular}{|c|c|c|c|c|c|c|}
\hline Variable & B & S.E. & Wald & $\mathrm{df}$ & Sig. & $\operatorname{Exp}(B)$ \\
\hline $\begin{array}{l}\text { The main reason for conduct of female } \\
\text { genital cutting }\end{array}$ & -.014 & .047 & .089 & 1 & .766 & .986 \\
\hline $\begin{array}{l}\text { The risk encountered when girls are } \\
\text { not subjected to female genital cutting }\end{array}$ & $.402-$ & .048 & 68.779 & 1 & .000 & .669 \\
\hline Constant & 1.625 & .245 & 44.025 & 1 & .000 & 5.078 \\
\hline
\end{tabular}

The "participants' daughters have been subjected to any form of FGC/M "was added as a predictor variable. Omnibus Tests of Model Coefficients give us a Chi-Square of 204.368 on $2 \mathrm{df}$, significant beyond .0001 . This is a test of the null hypothesis that adding the" daughters have been subjected to any form of FGC/M variable to the model has not significantly increased our ability to predict the decisions made the study participants.

The "Wald test" was conducted to recognize the significance of the logistic regression coefficients in the model. The calculated value of Wald test was smaller than the value of the level of significance used and accordingly the alternative hypothesis that the regression coefficients are accepted is assumed. As shown in Table No. (6), the regression coefficients can be explained as follows:

The variable "the risk encountered when girls are not subjected to female genital cutting" ranked the first place in influence as the regression coefficient of this variable is 68.779 .

The variable "the main reason for the conduct of female genital cutting" ranked the second place in influence as the regression coefficient of this variable is $\mathbf{. 0 8 9}$. 
Table (7): Reasons for not supporting eradication of female genital cutting

\begin{tabular}{|c|c|c|}
\hline $\begin{array}{c}\text { Reasons for not supporting eradication of female genital } \\
\text { cutting }\end{array}$ & Frequency & Percentage \\
\hline I support continuity of the FGC/M & 105 & 30.1 \\
\hline I support shifting to less traumatized forms of FGC/M & 183 & 52.7 \\
\hline Social pressures & 31 & 8.9 \\
\hline No clear reasons & 28 & 8.3 \\
\hline Total & 347 & 100 \\
\hline
\end{tabular}

$53 \%$ of the participants mentioned the reason for not supporting female genital cutting as they supported shifting to less traumatized forms of FGC/M while $30 \%$ of them supported continuity FGC/M.

Table (8): The main reasons for conduct of female genital cutting as perceived by the participants

\begin{tabular}{|c|c|c|}
\hline The reasons for conduct of female genital cutting & Frequency & Percentage \\
\hline Preservation of virginity & 232 & 25.2 \\
\hline Better marriage prospects & 51 & 5.5 \\
\hline Cleanliness/hygiene & 102 & 11.1 \\
\hline Customs \& traditions & 415 & 45.1 \\
\hline Religious & 52 & 5.7 \\
\hline Approval demanded by men & 27 & 2.9 \\
\hline I do not know & 36 & 3.9 \\
\hline Other & 5 & 0.5 \\
\hline Total & $\mathbf{9 2 0}$ & $\mathbf{1 0 0 . 0}$ \\
\hline
\end{tabular}

$45 \%$ of the participants mentioned customs and traditions as the main reason for conduct of FGC/M while $25 \%$ of them mentioned preservation of virginity and $6 \%$ mentioned religious reason. 


\section{Discussion}

About $89 \%$ of the study participants were married and $48 \%$ of them got married for the first time at age less than 20 years. $99.8 \%$ of the study participants were Moslems and $77.5 \%$ were currently urban residents. $86 \%$ of the study participants have had daughters and $32 \%$ of them have two daughters. $32 \%$ of them have one daughter less than 14 years. The median of the total monthly income of the participants' families in Sudanese pounds was 5,000 while the mean was 5,937 with SD \pm 5.937 . $88 \%$ of the participants' families practiced female genital cutting and the commonest age for such practice was 6-7 years as stated by about $48 \%$ of them. (Table 1 )

$53 \%$ of the study participants described girls who have never been subjected to FGC/M as Saleema while $28 \%$ described them as not circumcised and $18 \%$ as unclean (figure I). The result indicates the positive attitudinal change of the participants towards girls who have never been subjected to FGC/M and this is due to delivery of effective IEC messages and awareness rising about FGC/M practice.

$60 \%$ of the participants ever discussed female genital cutting with their husbands while $40 \%$ never discussed it as shown in figure (I1). $54 \%$ of the participants' husbands disagreed to female genital cutting while $43 \%$ of them agreed to it (table 2). The results reveal that the issue of FGC/M of daughters at the family level is still considered by a good proportion of the study participants as the responsibility of women rather men.

$39 \%$ of the participants stated that they themselves influence the decision to subject their daughters to female genital cutting while $32 \%$ of them stated that the grandmothers influence such decision (table 3). The result revealed that the influence of the decision to subject daughters to FGC/M is shouldered mainly by the mothers and grandmothers. The results are comparable to a recent study in Sudan, where 38.8\% of the respondents stated that mother's girls initiated the discussion on the need to conduct FGC/M and $37.6 \%$ of them identified the mother as the person involved in the decision of FGC/M (Eldin et al., 2018). Similar results were reported from Ethiopia, where the decision to have FGC/M was made by respondents' mothers, followed by grandmothers although the percentages were different (Gebremariam et al., 2016). Another study from Somali Region, Eastern Ethiopia reported that $70.3 \%$ of the respondents stated that FGC/M was decided by mother and $28.4 \%$ of them stated that both mother and father made the FGC/M decision and none of the participants 
mentioned that only father could decide by himself to conduct FGC/M for daughters (Abdisa et al., 2017).

$71 \%$ of the participants considered female genital cutting as a harmful traditional practice while $26 \%$ did not consider it as such (figure I11). The result revealed that the perception of most participants is inclined towards framing FGC/M as health issue and even a quarter of them did not perceive it as such. Such perception may be related to the delivered IEC message that focused on FGC/M health effects rather than addressing right-based and gender-based violence approaches.

The results indicate that less percentage of the participants perceived FGC/M as a violation of their rights and a form of gender-based violence against women and girls. Again, this might be related to the poor addressing of FGC/M as gender-based violence and violation of girls' and women's rights within the delivered IEC messages.

Some participants (38\%) were not supportive for eradication of FGC/M (figure V). A study among female rural dwellers in Egypt reported that $60.3 \%$ of the respondents supported the continuation of FGC/M (Abdisa et al., 2017). Another study from Eastern Ethiopia reported that $36 \%$ of the study, women supported the continuity of FGC/M (Hussein et al., 2013).

The attitude of participants' support of the eradication of FGC/M influences the conduct of FGC/M for the participants' daughters and as well the participants' approval of FGC/M for daughters who have never been subjected to any form of FGC/M. The results highlight the importance of participants' attitudes towards eradication of FGC and its influence in the conduct of FGC/M for daughters and approval of FGC/M conduct for daughters who have never been subjected to any form of FGC/M (table 5). The study participants' attitudes as reflected in the reasons for not supporting eradication of FGC/M indicate the tendency of the vast majority to shift to less traumatized FGC/M as mentioned by $50 \%$ of them while $30 \%$ of them frankly declared their support of continuity of FGC/M (table7).

The study revealed that FGC/M is socio-cultural practice as $45 \%$ of the participants believed in customs and traditions as the main reason to conduct of FGC/M while 25\% of them mentioned preservation of virginity and $6 \%$ mentioned religious reason (table7). A study from Ghana documented the important reasons for the conduct of FGC/M as traditions (44\%), control sexual desire (29\%) and social acceptance $20 \%$ (Berg et al., 2010). Another study from Easter Ethiopia reported important reasons for 
continuity of FGC/M as preservation of virginity $(61.8 \%)$, religious reasons $(18.1 \%)$ and avoidance of sex-related problems 13.4\%(Abdisa et al., 2017) .

$51 \%$ of the study participants stated that there was no risk at all while $20 \%$ of them mentioned rejection by husbands as the main risk if daughters were not subjected to female genital cutting (table 5). However, the prevalence of FGC/M among the participants' daughters is predictor of the risk encountered when girls are not subjected to FGC/M (Table 6).

$53 \%$ of the participants denied any benefits do girls themselves get if they are subjected to female genital cutting while $43 \%$ of them stated that there were benefits (figure VI). $34 \%$ of the participants who stated that there were benefits of female genital cutting mentioned the preservation of virginity and $23 \%$ of them mentioned cleanliness/hygiene as benefits of female genital cutting (Table 4). $72 \%$ of the participants stated that there are benefits do girls get themselves if they are not subjected to female genital cutting while $21 \%$ of them denied such benefits. $34 \%$ of the participants who stated that there were benefits of female genital cutting mentioned the preservation of virginity and $23 \%$ of them mentioned cleanliness/hygiene as benefits of female genital cutting (table 8). The results indicate the widely prevailing misconceptions about FGC/M among the study participants, especially among those participants supporting the continuation of FGC/M. Berg \& et al documented that that the continuance of FGC/M was largely attributable to cultural tradition, the interconnected factors, sexual morals and marriageability, religion, health benefits, and male sexual enjoyment. The belief that FGC/M was an important cultural tradition was the most influential factor(Berg et al., 2014) .

The reaction of the participants in case her daughter is rejected by her husband as she has not been subjected to FGC/M) varied from no reaction (34\%) to blaming the husband (28\%) and support conduct of FGC/M. However, the reaction of the participants is different in case son married and his wife has not been subjected to FGC/M as a higher percentage of the participants had no reaction and $7 \%$ would support conduct of FGC/M for the son's wife. The reasons for the different participant's reactions in the two situations may be related to varying degrees of the social pressure and criticisms induced by other family and community members. Moreover, in communities where FGC/M is almost universally practiced, not conforming to the practice can result in stigmatization, social isolation and difficulty in finding a husband(Gruenbaum, 2005). 


\section{Conclusion}

FGC/M is deeply rooted belief of the participants' families and thus most of the participants' families accepted it as social norms. FGC/M is socio-cultural practice as $45 \%$ of the participants believed in customs and traditions as the main reason for conduct of $\mathrm{FGC/M}$ while $25 \%$ of them mentioned preservation of virginity and $6 \%$ mentioned religious reason. The study participants attitudes as reflected in the reasons for not supporting eradication of FGC/M indicate the tendency of the vast majority to shift to less traumatized FGC/M as the results indicate the widely prevailing misconceptions about FGC/M among the study participants especially among those participants supporting the continuation of FGC/M.

It is necessary to adopt wide community-based interventions that address FGC/M holistically rather than a health issue ,but as a violation of girls' and women rights and gender-based violence. The intervention strategies at the community level should be shifted towards behavioral communication change (BCC) with involvement of families and individuals to abandon the FGC/M practice. 


\section{References}

Abdisa, B., Desalegn, M., \& Tesew, A. (2017). Assessment of the Prevalence of FGM and Associated Factors among Women's of Reproductive Age Group in Kebirbeyah Town, Somali Region Eastern Ethiopia, 2017. Health Science Journal, 11(4), 1-9. https://doi.org/10.21767/1791-809x.1000517

Berg, R. C., Denison, E., \& Fretheim, A. (2010). Factors promoting and hindering the practice of female genital mutilation/cutting (FGM/C). In Kunnskapssenteret (Issue 23).

https://brage.bibsys.no/xmlui/bitstream/handle/11250/2378443/NOKCrapport23_20 10.pdf?sequence $=1 \&$ is Allowed $=y$

Berg, R. C., Underland, V., Odgaard-Jensen, J., Fretheim, A., \& Vist, G. E. (2014). Effects of female genital cutting on physical health outcomes: A systematic review and meta-analysis. BMJ Open, 4(11), 1-12. https://doi.org/10.1136/bmjopen-2014-006316

Cuba Multiple Indicator Cluster Survey 2014 _ GHDx. (n.d.).

Eldin, A. G., Babiker, S., Sabahelzain, M., \& Eltayeb, M. (2018). FGM/C Decision-Making Process and the Role of Gender Power Relations in Sudan. October. https://knowledgecommons.popcouncil.org/cgi/viewcontent.cgi?article=1549\&cont ext=departments_sbsr-rh

Evaluation Branch DOS. (2012). Evaluation of UNFPA Support to Maternal Health; Mid-Term Evaluation of the Maternal Health Thematic Fund. 68.

Female Genital Mutilation/Cutting: a statistical overview and exploration of the dynamics of change. (2013). In Reproductive Health Matters (Vol. 21, Issue 42, pp. 184-190). https://doi.org/10.1016/s0968-8080(13)42747-7

Gebremariam, K., Assefa, D., \& Weldegebreal, F. (2016). Prevalence and associated factors of female genital cutting among young adult females in Jigjiga district, eastern Ethiopia: A cross-sectional mixed study. International Journal of Women's 
Health, 8, 357-365. https://doi.org/10.2147/IJWH.S111091

Gruenbaum, E. (2005). Socio-cultural dynamics of female genital cutting: Research findings, gaps, and directions. In Culture, Health and Sexuality (Vol. 7, Issue 5, pp. 429-441). https://doi.org/10.1080/13691050500262953

Hussein, M., Adem, A., \& Mohammed, M. (2013). Knowledge, attitude and practice of female genital mutilation among women in Jigjiga Town, Eastern Ethiopia. Gaziantep Medical Journal, 19(3), 164. https://doi.org/10.5455/gmj-30-2013-157

Mseddi, M., Bouassida, S., \& Turki, H. (2006). Female genital mutilation. In Sexologies (Vol. 15, Issue 4, pp. 262-265). https://doi.org/10.1016/j.sexol.2006.05.002

WHO. (2015). HEALTH IN 2015: FROM MDGs TO SDGs. In Harvard International Review (Vol. 37, Issue 1, pp. 1-14).

Wright, J. (1996). Female genital mutilation: An overview. Journal of Advanced Nursing (Vol. 24, Issue 2, pp. 251-259). https://doi.org/10.1046/j.1365-2648.1996.01934.x

\section{Declarations}

\section{Ethical considerations:}

An ethical approval was obtained from the Research Ethics Committee at Federal Ministry of Health. In addition, permissions were obtained from the authorities of the 
selected localities, administrative units and popular committees. An informed consent was obtained from each study participant prior to the interview. The collected data were kept confidential and accessed only by the research team members.

\section{Availability of data and materials}

Data are available on relevant request .

\section{Authors' contribution}

MKM Elnimeiry was a the principal investigator of the study and took the leading role from the conception design to the final implementation of the project, and overall writing and revision of the manuscript.

S Satti took final write-up of the manuscript TM statistical analysis and revision of manuscript

MKM Revision of manuscript

RM data collection and revision of manuscript

DA data collection and revision of manuscript

\section{Consent for publication}

All authors reviewed the manuscript, and approved the final version for publication.

\section{Competing interests}

The authors declare that they have no competing interests.

\section{Acknowledgements}

We would like to express our heartfelt thanks to the study participants, data collectors for their participation in this study.

\section{Fund}

This project fully funded by Sudan Family Planning Association 

Figures

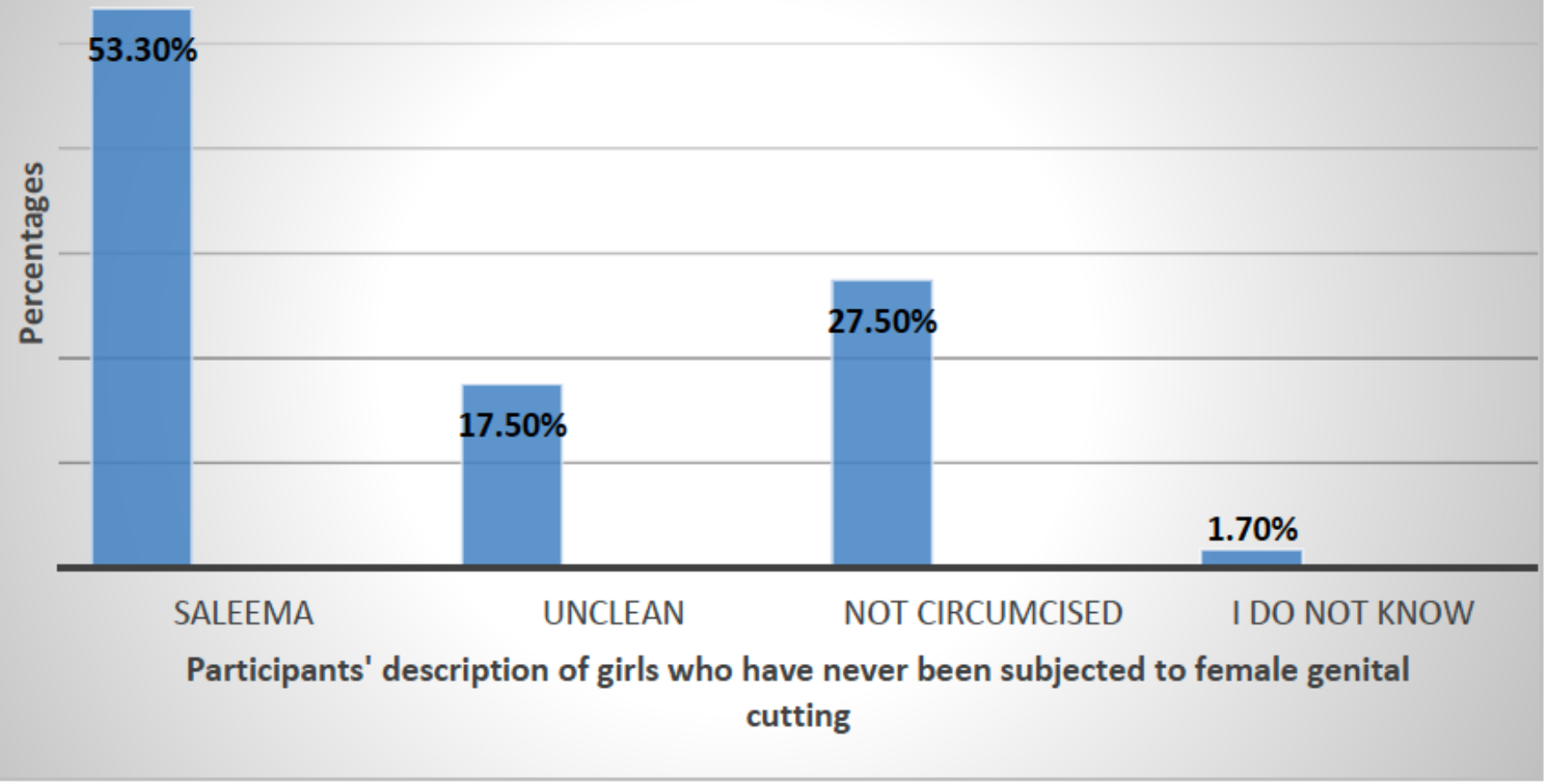

Figure 1

Participants' description of girls who have never been subjected to female genital cutting

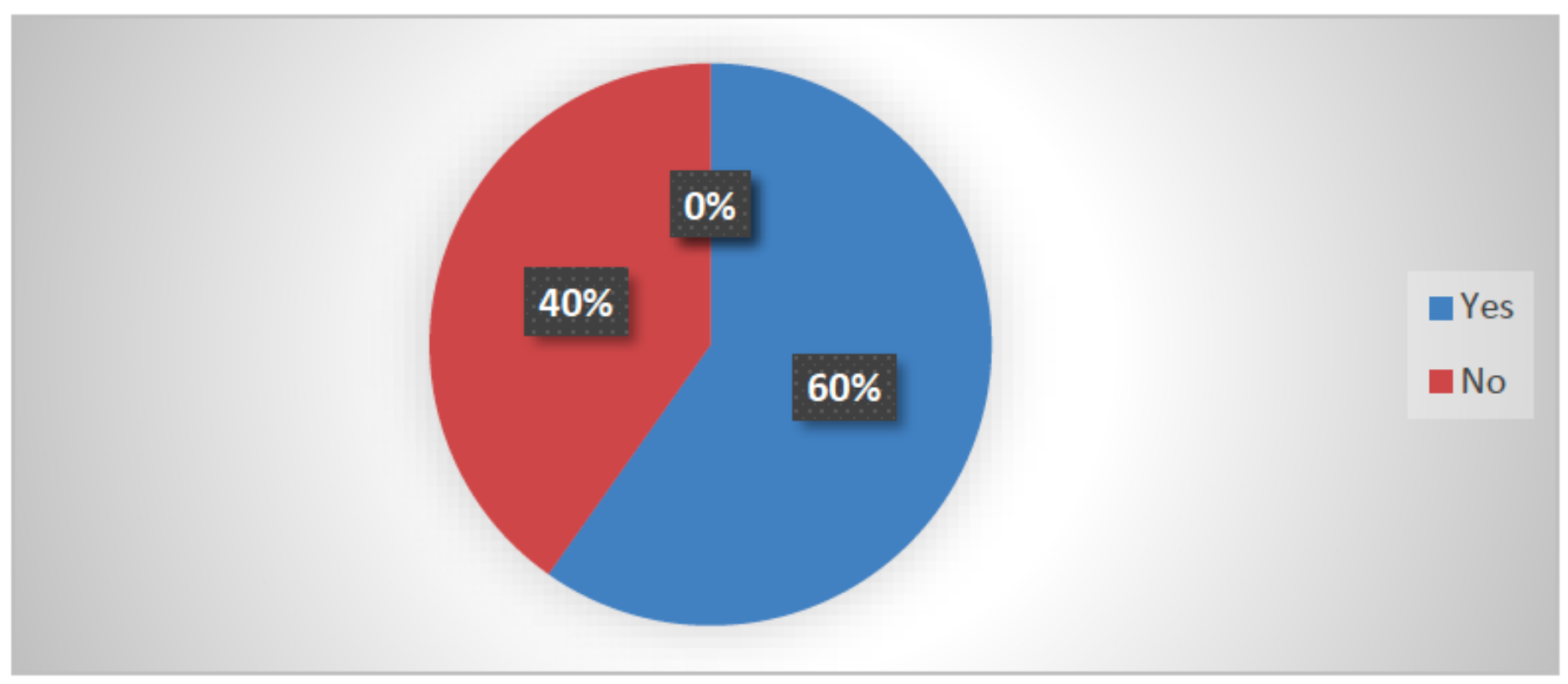

Figure 2 
Participants ever discussed female genital cutting with husbands $60 \%$ of the participants ever discussed female genital cutting with their husbands while $40 \%$ never discussed it.

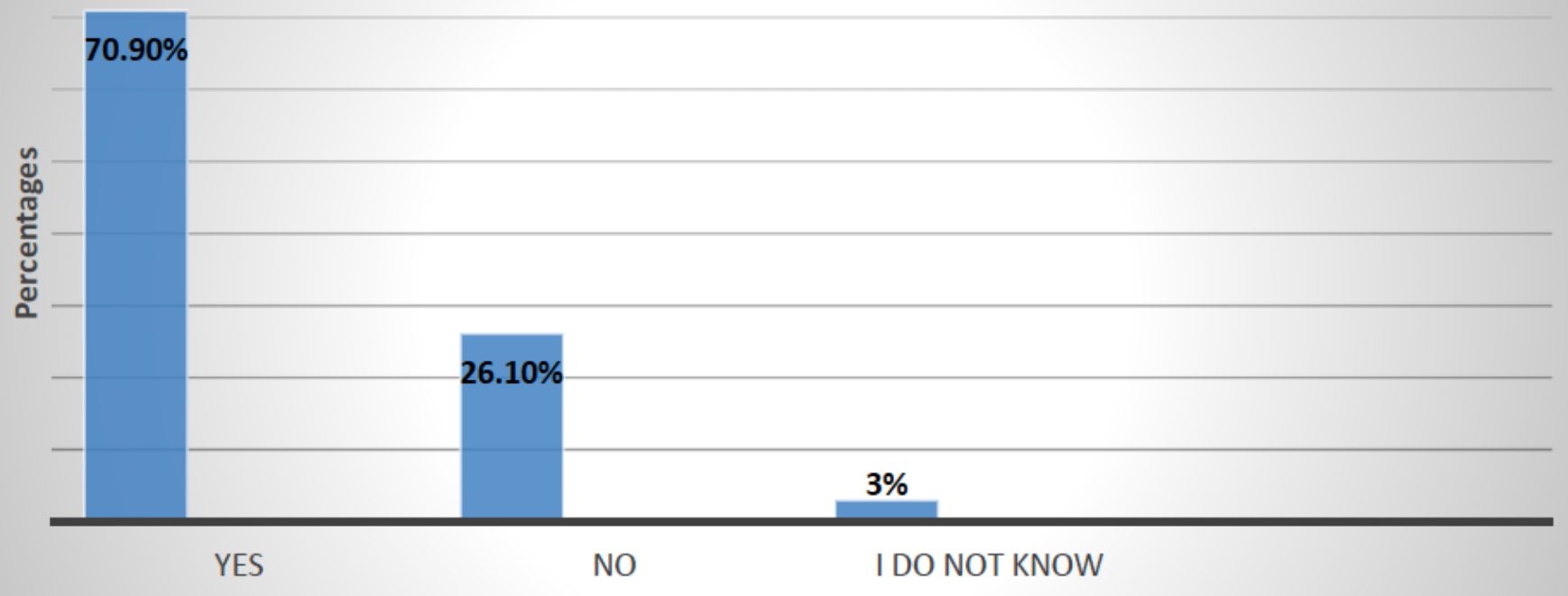

Participants who consider female genital cutting as a harmful traditional practice

\section{Figure 3}

Participants consider female genital cutting as a harmful traditional practice

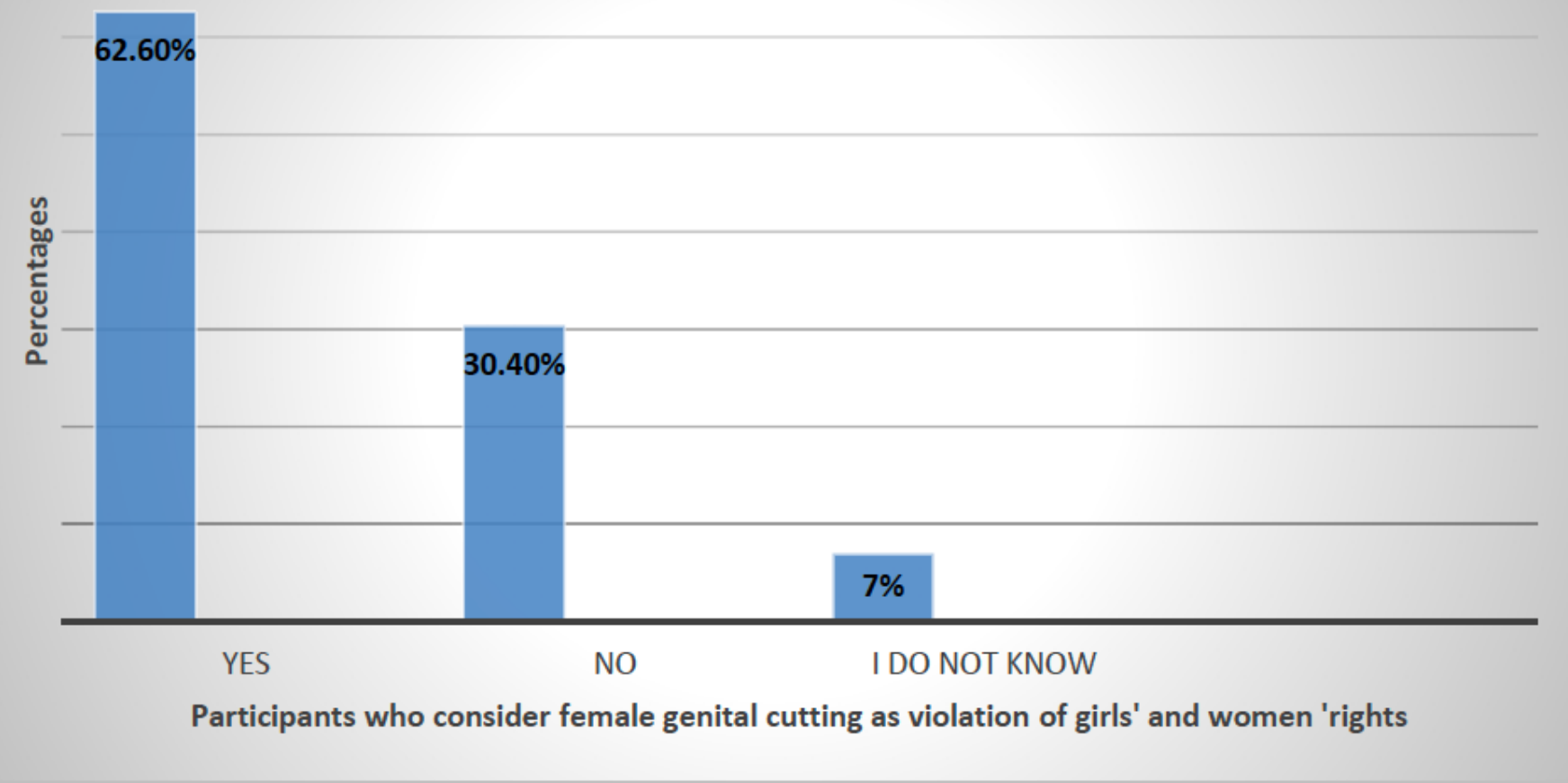


Participants consider female genital cutting as a violation of girls' and women's rights

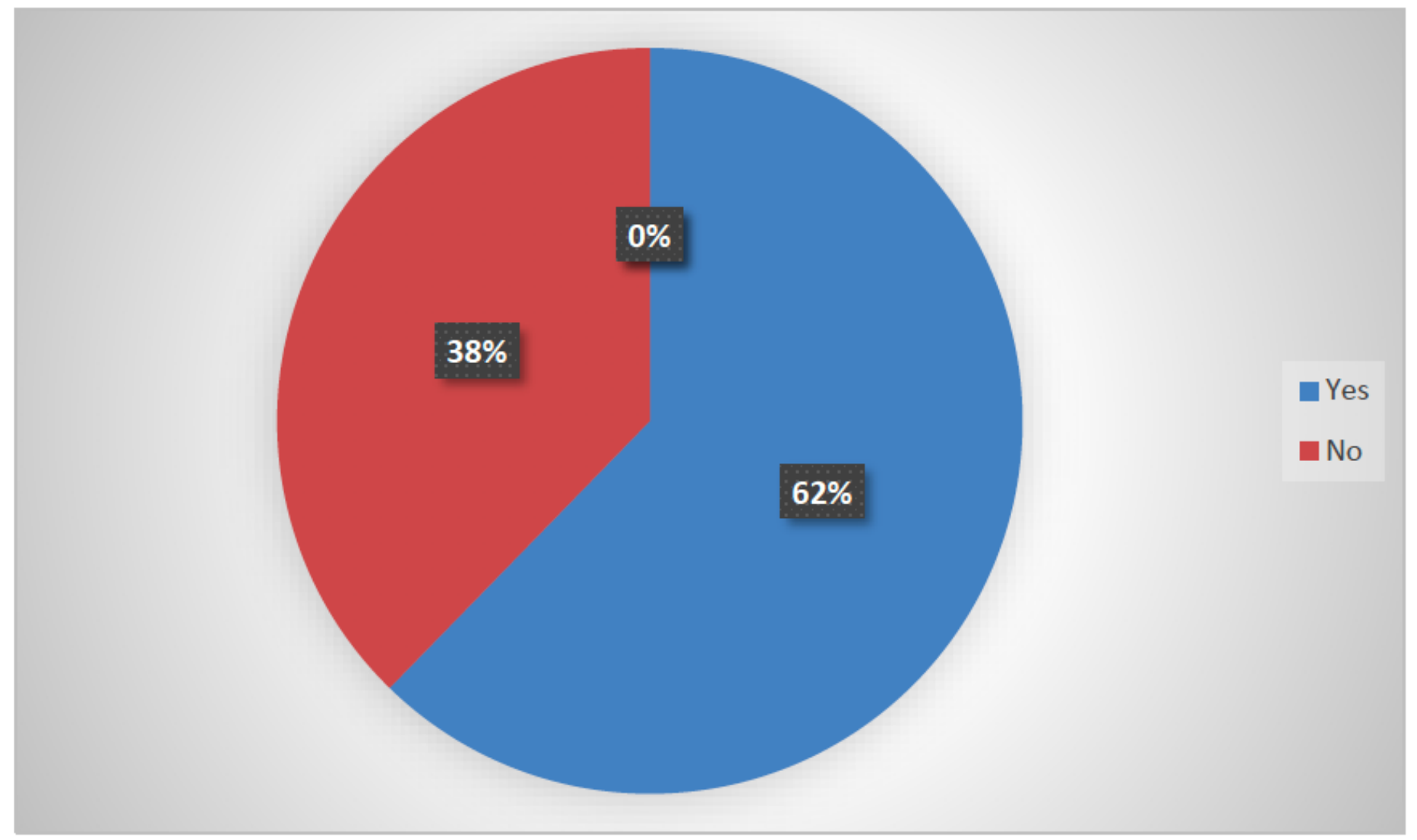

\section{Figure 5}

Participants support eradication of female genital cutting 


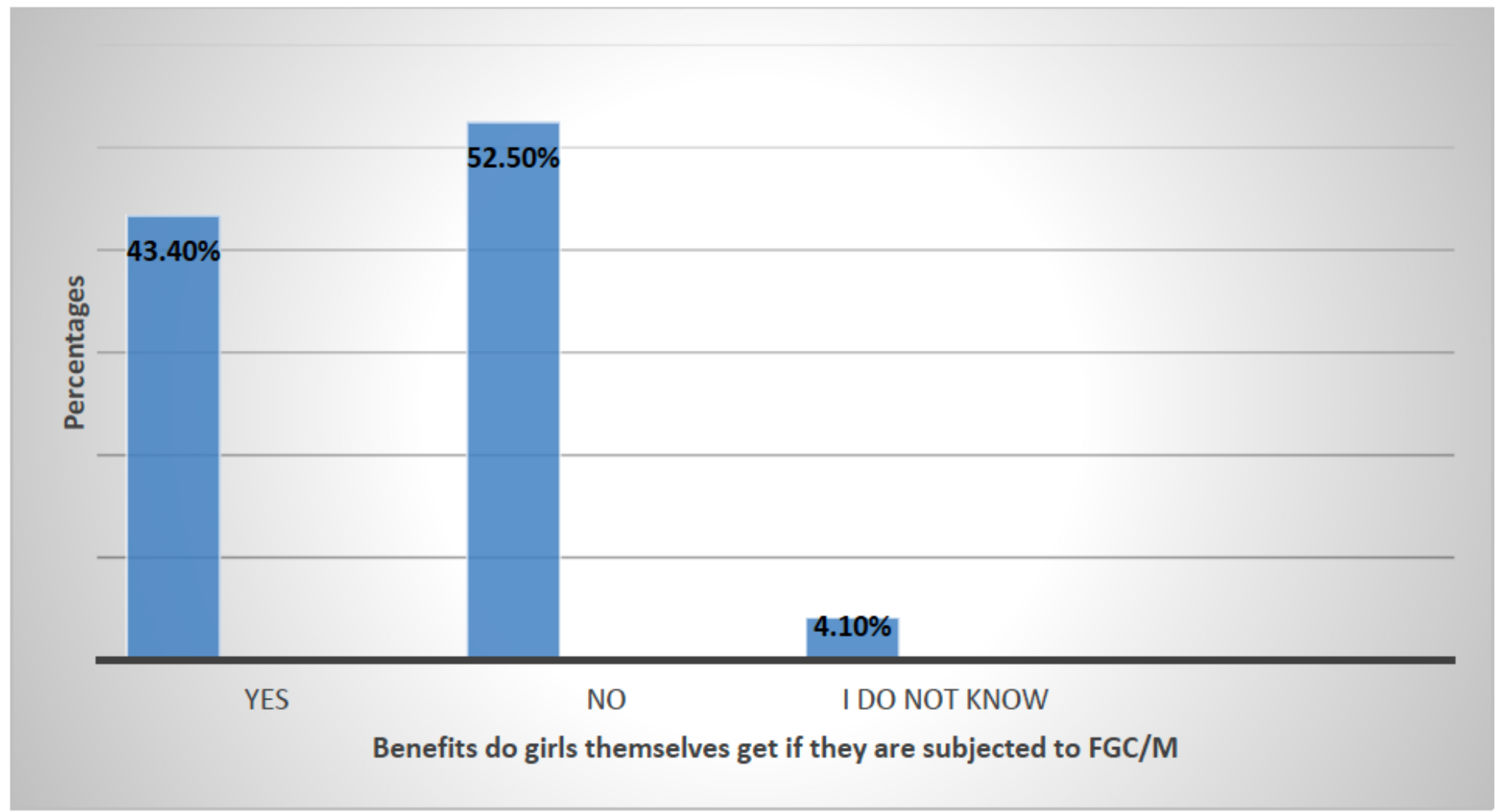

Figure 6

Benefits do girls themselves get if they are subjected to female genital cutting 